\title{
Üniversite Öğrencilerinin Kayırmacılık Kavramına İlișkin Metaforik Algıları
}

\author{
Nesip DEMiRBiLEK'
}

\begin{abstract}
Öz: Araştırmanın amacı üniversite öğrencilerinin kayırmacılık kavramını nasıl kavramsallaştırdıklarını ve algıladıklarını metaforlar aracılığı ile belirlemektir. Araştırmada nitel araştırma yöntemlerinden fenomenoloji yaklaşımı benimsenmiş, katılımcıların seçilmesinde ise kolay örnekleme tekniği kullanılmıştır. Araştırmada 2020-2021 eğitim-öğretim yılında Muş Alparslan Üniversitesinde öğrenim gören toplam 159 öğrenci yer almıştır. Üniversite öğrencilerine metafor cümlesi online olarak gönderilmiştir. Verilerin analizinde "içerik analizi" tekniğinden yararlanılmıştır. Araştırma sonuçlarına göre üniversite öğrencilerinin ürettiği metaforlar ile oluşturulan kategorilerin toplam sekiz kategori başlı̆̆ altında yer aldığı görülmüştür. Sonuç olarak Muş Alparslan Üniversitesi öğrencilerinin ifadelerinden hareketle kayırmacılığın, büyük zararları olan, sosyal bir davranış bozukluğu olduğu ve toplumun çoğunu olumsuz etkilediği sonucuna varılmıştır.
\end{abstract}

Anahtar Sözcükler: Kayırmacılık, Ayrımcılık, Eşitsizlik, Adaletsizlik, Liyakat

\section{Metaphoric Perceptions of University Students on the Concept of Favoritism}

\begin{abstract}
The aim of the study is to determine how university students conceptualize and perceive the concept of favoritism through metaphors. The phenomenology approach, one of the qualitative research methods, was adopted in the study, and the easily accessible technique was used in the selection of the participants. 159 students studying at Mus Alpaslan University in the 2020-2021 academic year were included in the research. The metaphor sentence was sent online to university students. The "content analysis" technique was used to analyze the data. According to the results of the research, it was seen that the categories created with the metaphors produced by university students were under the headings of eight categories in total. As a result, based on the statements of Muş Alparslan University students; It was concluded that favoritism is a social behavioral disorder that has great harm and negatively affects most of the society.
\end{abstract}

Keywords: Favoritism, Discrimination, Inequality, Injustice, Merit 
Yolsuzluk olgusunun, insanların örgütlenerek topluluk halinde yaşamaya başladığı andan itibaren ortaya çıktığını söylenebilir. Nitekim toplumsal hayata geçiş, bireyler arası etkileşim, sosyal alışveriş sürecini de doğal olarak doğurduğu için bu ihtimal güçlenmektedir. Başka bir deyişle, yolsuzluk insanlık tarihi boyunca var olagelmiştir. Yolsuzluğun bir çeşidi olan kayırmacı tutum ve davranışların tarihî köklerinin antik çağlara kadar uzandı ̆̆ını değişik yerlerde farklı dönemlerde yapılan arkeolojik çalışmalar ile bilinmektedir. Örneğin; Platon kız kardeşinin oğlunu, maddi açıdan yoksul olduğu gerekçesiyle kendisinden sonra akademinin yöneticisi olarak görevlendirmiştir (Çarıkçı ve Arslan, 2010).

Yolsuzluk, rüşvet gibi maddesel çıkar veya kayırma gibi maddesel olmayan çıkarlar doğrultusunda kamusal yetkinin kötüye kullanılmasına neden olan tüm eylem ve davranışları kapsamaktadır. Yolsuzluk terimi maddesel olan-olmayan şeklinde sınıflandırılmakta ve kayırmacılık, maddesel olmayan bir yolsuzluk türü olarak aktarılmaktadır (Berkman, 1983). Aktan (2001) ise rüşvet, zimmet, rant, kollama, irtikâp ve adam kayırmacılık gibi davranış ve eylemlerin tümü şeklinde kategorize etmektedir. Berkman (1983) ve Aktan'ın (2001) yapmış oldukları tanımlardan hareketle, kayırmacilık, yolsuzluk (bir görevi veya yetkiyi kötüye kullanma durumu) türlerinden biri olarak belirtilmiştir. Fakat kayırmacılık diğer yolsuzluk türlerinden (rüşvet, zimmet, rant kollama, irtikâp) farklıdır. Kayırmacılık meslek etiğine aykırı ve profesyonel olmadığı için eleştirilmesine rağmen (Abdalla, Maghrabi ve Raggad, 1998), direkt olarak mal ya da para değiş tokuşu olmadığ için rüşvet gibi yolsuzluk şekillerinden ayrılmakta ve kısmen kabul edilebilir bir olgu olarak görülmektedir (Loewe, Blume ve Speer, 2008; Özler ve Büyükarslan, 2011). Yolsuzluk türü olarak kabul edilen kayırmacılık yolsuzluğunda doğrudan değiş tokuş olmamasına rağmen genellikle dolaylı bir değiş tokuş alışverişi vardır. Süreç taraflar açısından ele alındığında, dolaylı da olsa haksız bir çıkar alışverişi şeklinde olduğu söylenebilir. Kayırılan tarafın, hak etmediği bir şekilde ayrıcalık, öncelik ve imtiyaz kazandığı ifade edilebilir. Kayıran taraf açısından ise kayırmacı tutumunun karşılığı olarak bir siyasetçinin oylarını artırması, bir yöneticinin maddi olarak çıkar sağlaması, bir grubun (dernek, kulüp, birlik, akraba topluluğu vb.) güçlendirilmesi, vefa borcunun ödenmesi gibi birçok şey olabilir (Erdem, 2010).

Kayırmacılık, bir kişi veya grubun çıkar sağlamasına yönelik olarak yapılan hak ve adaletten sapma eğilimidir. Menfaat sağlama üzerine birilerine öncelik tanımak ve ayrıcalık sağlamaktır. Ayrıcalıklı ve öncelikli davranıştan fayda gören örgüt veya birey arasındaki yakın ilişki ağları etrafında oluşturulan çarpık bir ilişki şeklidir ve çeşitlenen dayanakları ile vuku bulabilmektedir (Aytaç, 2010a). Erdem'e (2010) göre akraba, eş-dost ve hemşeri kayırmacılı̆̆ı, çıkar ve ideolojik merkezli kayırmacılık, olarak beş başlıkta; Kayabaşı'na (2005) göre ise politik bir yozlaşma türü olan kayırmacılık; adam, siyasal ve hizmet kayırmacılığı olmak üzere üç ayrı başlık altında incelenebilir. Bu araştırmada kayırmacılık bir üst çatı olarak belirlenmiş ve türleri ayrıca tasnif edilmiştir.

Türk toplumunun kamu kurum ve kuruluşlarındaki işleyişte, "adamını bulmak" iş görme biçimlerinden birisi olduğu belirtilmektedir. Örneğin, çocuğunun üniversitedeki notlarının yükseltilmesinden hastanede iyi muamele görebilmeye, fatura ödemelerinin halledilmesinden tayin işlerine, iş ve işçi bulmaktan pazar alışverişlerine kadar gündelik hayatı ilgilendiren pek çok konuda "adam" başvuru kaynaklarının başında gelmektedir (Kurtoğlu, 2012). Kayırmacılık olarak tanımlanan bu olgu, Türk toplumunun sosyal bir gerçeği olarak açıklanmaktadır (Akalan, 2006). Nitekim pek çok araştırmacı kamu kurumlarında yaptıkları araştırmaların sonucunda adam kayırmacılığının yaygınlığına dikkat çekmektedirler (Argon, 2016; Aydoğan, 2009; Aytaç, 2010a; Aytaç, 2010b; Geçer, 2015; Uçar, 2016).

Comerford (2002), Kanada hükümeti çalışanları üzerinde yapmış olduğu bir araştırmada, iş yükünden sonra işyeri çatışmasının en önemli ikinci kaynağının kayırmacılık olduğunu belirtmiştir (akt: Kwon, 2006). Etik olmayan bir davranış olarak kabul edilen kayırmacılık (Polat ve Kazak, 2014) hem örgütsel hem de günlük hayatta karşılaşılabilen ve sosyal sistemlerin bulunduğu hemen her alanda ortaya çıkabilen bir olgudur (Özkanan ve Erdem, 2014). Örneğin, “Üniversite Gençliğinin Sosyolojik Profili - 2001", adlı araştırmada 3223 üniversite öğrencisine uygulanan bir ankette, "Türkiye'de çok çalışan değil, dayısı olan kazanıyor" önermesine; örneklemin \%90 gibi bir çoğunluğu "evet" yanıtını vermiştir. Araştırmada "siyasetçilerin gerçek amacı nedir?" sorusuna, örneklemin \%75'i yakınlarına, yandaşlarına, yoldaşlarına vb. çıkar sağlamak ve zengin olmak şeklinde cevaplamıştır. Bu örneklemin oranı istatiksel açıdan değerlendirildiğinde çok ciddi 
sorunları ortaya çıarabilecek bir veri olarak değerlendirilebilir. Anlam bakımından değerlendirildiğinde ise bürokrasiye, siyasete ve devleti yönetenlere özellikle güvensizliğin bir göstergesi olarak nitelendirilebilir. Kayırmacı tutum ve davranışlar, kamu kurum ve kuruluşlarını gerçek amaçlarından saptırmakta ve bireylerin adalet algılarını bozmaktadır (Polat ve Kazak, 2014). Kayırmacılık, örgütler içinde ortaya çıkan olumsuz sosyal sonuçların öncüllerinden biri olarak görülmektedir (Sakçak, Arslan ve Polat, 2021). Bu araştırmada bahse konu olan, geleceğin teminatı olarak görülen üniversite öğrencilerinin, motivasyon açısından içerisine düştükleri olumsuz tutumun ülkenin toplumsal kalkınmasına ve gelişmesine etkilerinin de olumsuz olarak yansıyabileceği söylenebilir.

Kayırmacılık (Favoritism) kavramının yerli literatürde zaman zaman nepotizm ve kronizm kavramı ile eş anlamda kullanıldı̆̆ı (Aktan, 2001; Büte, 2011; Çelik ve Erdem, 2012; Erden, 2014; Kayabaşı, 2005) görülmektedir. Ancak kayırmacılık, nepotizm ve kronizm kavramlarını da içeren ve bünyesinde farklı türler bulunduran daha kapsamlı bir kavram olarak aktarılmaktadır (Asunakutlu ve Avc1, 2010). Nitekim Türk Dil Kurumunun Bilim ve Sanat Terimleri Ana Sözlüğ̈̈ ‘ne göre kayırmacılığın İngilizce karşılığı favoritism olarak belirtilmiştir. Belli bir birey, küme, düşünce ya da olayı, bir başkası ile kıyaslayıp aralarında bir tercih yapmak gerektiğinde taraflı davranarak bir tarafı tutma olarak tanımlanmaktadır (TDK, 2021). Ayrıca nepotizm ve kronizmin, kayırmacılığın kişisel ilişkilerden (akrabalık/arkadaşlık) kaynaklı türlerinden olduğu belirtilmiştir (Araslı ve Tümer, 2008; Bayhan, 2002; Karaköse, 2014; Özler ve Büyükarslan, 2011; Özler, Özler ve Gümüştekin, 2007). Bu karmaşaya ışık tutması bakımından kayırmacılık kavramına ilişkin algıların metaforlar aracılığıyla ortaya çıkarılmasına ihtiyaç olduğu düşünülmektedir.

Metaforlar, bir şeyi başka bir şeyin bakış açısıyla anlayıp deneyimlemek şeklinde ifade edilmektedir. Kişiler kendilerinin ve karşısındakilerin düşünce ve duygularını tanımlarken metafordan yararlanmaktadırlar. Bu da kişilerin kendilerini ve dünyayı nasıl algıladıklarını açığa çıkarmaktadır. Metaforlar, bireyin tecrübesinin anlaşılmasını sağlayarak bireyin dünyasına ilişkin bilgi sahibi olunmasını ve tanımlanmasını sağlamaktadır (Lakoff ve Johnson, 2015). Aynı zamanda metaforlar bir tecrübeyi başka bir tecrübeye göre anlaşılmasını ve anlamlandırılmasını sağlayan araçlar olup bireylerin bilişsel yaklaşımlarını yansıtmaktadır (Tepebaşılı, 2013). Metaforlar, kişilerin kendi dünyalarını anlayıp yapılandırmalarına yönelik güçlü bir modelleme ve zihinsel haritalama mekanizmaları olması sebebiyle dikkat çekmektedir. Metaforlar, bilinmeyenlerin öğretilmesinde mükemmel bir teknik, öğrenilen bilgilerin zihinde tutulup hatırlanması konusunda geçerliliği ispatlanmış araçlar olarak görülmektedir (Arslan ve Bayrakçı, 2006). Metaforların araştırmalarda kullanmanın çekiciliği, bireylerin bilgi ve yaşam deneyimlerini birbirleri ile ilişkili ve manidar kılma kapasitesinde saklıdır (Tepebaşıll, 2013).

Metaforların eğitim araştırmalarında kullanmanın avantajlarından biri kavramı odak kitleyle etkili bir iletişim kuracak biçimde betimlemek, açıklamak ve tasvir etmektir (Güveli, İpek, Atasoy ve Güveli, 2011). Dolayısıyla, metaforlar bireyin farkında olmadığı duygu ve düşüncelerinin de ortaya çıkarılması açısından önem taşımaktadır. Bu veriler ışı̆̆ında, bireylerin dahi kendi bilişsel tabularının ve dünyalarının farkında olmadan kullandıkları metaforların ortaya çıkarılması ve bireylere kendi iç dünyalarına ilişkin geri bildirimde bulunulması önem arz etmektedir. Literatür incelendiğinde metaforlar aracıllğılyla yapılan birçok araştırmanın olduğu ve eğitimle etkileşim içinde olan bireylerin metaforik algılarıyla ortaya konulmaya çalışıldığ1 görülmektedir (Demirbilek, 2020; Demirbilek, 2021a; Demirtaş ve Çoban, 2014; Demirbilek ve Korkmaz, 2021; Kalyoncu, 2012; Nalçacı ve Bektaş, 2012; Özdemir, 2012; Yalçın ve Erginer, 2012). Kayırmacılık kavramının, üniversite öğrencilerini konu alan araştırmaların ise olmadığı, bu sebeple önem arz ettiği düşünülmektedir.

Sosyal davranış bozukluğu olan kayırmacı uygulamaların izdüşümleri, eğitim alanında da görülmekte; okullardaki işe uygunluk, layık olma, ehil olma, hak etme gibi pozitif değerleri ihtiva eden liyakat ilkesine ciddi zararlar vermekle birlikte okulların verimli ve etkili olmasını engellemektedir (Argon, 2016; Demirtaş ve Demirbilek, 2019). Üniversite öğrencilerinin kayırmacılık kavramına ilişkin algılarının ortaya çıkarılması ile kavrama ilişkin yaşanan karmaşanın giderilmesi ve eğitim kurumlarının verimli ve etkili olmasını engelleyen kavramın konu edinilmesi bakımından alana katkı sağlayacağı öngörülmektedir. Bu verilerden hareketle bu araştırmada üniversite öğrencilerinin, kayırmacılık kavramına ilişkin metaforlarını (zihinsel imgeleri) ortaya 
çıkarmak amaçlanmıştır.

\section{Araştırmanın Amacı}

Araştırmanın amacı, üniversite öğrencilerinin kayırmacılık kavramını nasıl algıladıklarını ve kavramsallaştırdıklarını metaforlar aracılığı ile tespit etmektir. Bu bağlamda aşağıda belirtilen sorulara cevaplar aranmıştır.

1. Üniversite öğrencilerinin kayırmacılık kavramına yönelik metaforları nelerdir?

2. Üniversite öğrencilerinin kayırmacılık kavramına yönelik oluşturdukları metaforlar, benzer özellikler bakımından hangi kategoriler altında toplanmaktadır?

\section{Yöntem}

\section{Araştırmanın Modeli}

Araştırmada nitel araştırma yöntemlerinden fenomenoloji deseni kullanılmıştır. Fenomenoloji, bireylerin kendi yaşam dünyalarının kasıtlı bir deneyimi ve toplumsal eylemidir (Schram, 2003). Bu desen; günlük yaşantılarda, olaylar, deneyimler, algılar, yönelimler ve kavramlar gibi çeşitli biçimlerde ortaya çıkabilen aynı zamanda farkında olunan fakat derinlemesine ve detaylı bir anlayışa sahip olunmayan olgulara odaklanmaktadır (Yıldırım ve Şimşek, 2016). Başka bir ifade ile, araştırmaya dahil edilen katılımcıların tecrübe etmiş oldukları olgulara ilişkin açıklamaları incelenerek, zihinlerindeki algı ve beklenti gibi bilişsel yapıların açı̆̆a çıkartılmasıdır (Creswell, 2017; Patton, 2014).

\section{Katılımcilar}

Katılımcıların seçilmesinde olasılığı bilinmeyen örnekleme yöntemlerinden kolay ulaşılabilir örnekleme tekniği kullanılmıştır. Bu teknik ile katılımcıların belirlenmesinde, bir evrenden evreni temsil edebilecek büyüklükte rastgele örneklem seçilmektedir (Fraenkel, Wallen ve Hyun, 1993). Ayrıca, araştırma konusu ile ilişkisi olan ve araştırmacının kolay bir şekilde ulaşabileceği kişilerden faydalanılmaktadır (Yıldırım ve Şimşek, 2016). Araştırmanın amacı doğrultusunda, 2020-2021 eğitim öğretim yılında Muş Alparslan Üniversitesinde öğrenim gören 224 öğrenciye ulaşılmıştır. Öğrencilere, Muş Alparslan Üniversitesinde akademisyen olarak görev yapan tanıdık hocalar vasıtası ile erişilmiştir. Ancak, kayırmacılık kavramına ilişkin hatalı metafor oluşturan ya da oluşturmak istemeyen 65 katılımcının formu elenmiştir. Sonuç olarak, araştırma 159 form ile yürütülmüştür.

Tablo 1. Üniversite Öğrencilerine İlişkin Bilgiler

\begin{tabular}{llrr}
\hline Değişkenler & Kategori & $\mathbf{N}$ & $\mathbf{\%}$ \\
\hline \multirow{2}{*}{ Cinsiyet } & Kadın & 101 & 63,5 \\
& Erkek & 58 & 36,5 \\
\hline \multirow{2}{*}{ Bölüm bilgisi } & Sayısal bölümler & 61 & 36,1 \\
Toplam öğrenci Sayısı & Sözel bölümler & 98 & 62,3 \\
\hline
\end{tabular}

\section{Verilerin Toplanması}

Araştırmanın etik kurul izni, Bingöl Üniversitesi Bilimsel Araştırma ve Yayın Etiği Kurul komisyonundan alınmıştır. Araştırmada, "Google Forms" ortamında, form oluşturulmuştur. Form içerisinde katılımcılardan, kişisel bilgiler ile birlikte "Kayırmacılık ........ gibidir/benzemektedir, çünkü ......" cümlesini doldurmaları istenmiştir. Ayrıca, metaforun ne olduğu ve nasıl kullanıldığına ilişkin hem açıklamalarda bulunulmuş hem de örnekler verilmiştir (Kılcan, 2017). Hazırlanan formlar, online (WhatsApp, e-posta) olarak gönderilmiş ve aynı şekilde toplanmıştır. Hazırlanan form iki ay boyunca erişime açık tutulmuştur.

\section{Verilerin Analizi}

Araştırmanın analizinde içerik analizi yöntemi kullanılmıştır. İçerik analizi, belirli kurallara bağlı kalınarak kodlamalar yapılması ve bir metnin bazı kelimelerini daha küçük içerik kategorileri ile açıkladığı 
sistematik, yenilenebilir teknik olarak betimlenmektedir (Büyüköztürk ve diğerleri, 2008). Balc1 (2016) içerik analizini; insanların konuştukları ve yazdıklarını açık beyanlara göre kodlanarak sayısallaştırma süreci olarak tanımlamaktadır. Araştırmanın içerik analizinde aşağıdaki beş aşamalı değerlendirme süreci kullanılmıştır (Creswell, 2017; Demirbilek, 2021a; Saban, 2008): 1. Adlandırma ve Eleme Aşaması, 2. Tasnif Etme Aşaması, 3. Kategori Geliştirme Aşaması, 4. Geçerlik ve Güvenirliği Sağlama Aşaması, 5. Nicel Veri Analizi için Verilerin Düzenlenmesi Aşamasıdır.

Araştırmanın ilk aşamasında üniversite öğrencileri tarafından oluşturmuş metaforların alfabetik listesi yapılmış ve araştırmanın amaçları doğrultusunda üretilip üretilmediğine bakılmıştır. "Kayırmacılık" kavramını metafor olarak açıklayamayan veriler elenmiştir ( $f=65)$. Toplam 159 form ile araştırma yürütülmüştür. Kalan tüm anketlere birer anket numarası verilmiştir. Değerlendirmeye alınan metaforlara ait formlar için "katılımcı" kavramının kısaltması olarak düşünüldüğünden dolayı 1K, 2K... 159K şeklinde kodlanmış ve numaralandırılmıştır.

Araştırmanın ikinci aşamasında içerik analizi kullanılmış her metafor tek tek okunmuş ve tasnif edilmiştir. Araştırmanın üçüncü aşamasında öğrenciler tarafından yazılan metaforlar ortak ve benzer özellikleri bakımından bir araya getirilerek farklı kategoriler altında toplanmıştır. Araştırmacı tarafından kayırmacılık kavramına ilişkin sekiz farklı kategori geliştirilmiştir. Verilerin kategorilere ayırma işleminde, öğrenciler tarafından yapılmış olan açıklamalara göre hareket edilmiştir. Nedenleri farklı metaforları aynı olan veriler, farklı kategorilere alınmıştır. Örneğin; "Kayırmacılık torpile benzer, çünkü parası olan diğerlerinden ayrı tutarlar (20K)." cümlesindeki torpil metaforu eşitsizliğin, adaletsizliğin ve ayrımcilığın olması kategorisine alınırken "Kayırmacılık torpil gibidir, çünkü onu başka şeylerden üstün tutarlar hak edenin hakkı gözetilmez (82K)." cümlesindeki torpil metaforu ise hak edenin emeğinin çalınması ve yaşamdan soğutması kategorisine alınmıştır.

Elde edilen metaforların sunumunda, yazılı yanıtların görselleştirilmesi yoluyla anlaşılırlığı ve erişilebilirliği arttırabilmek için "Kelime Bulutları" tercih edilmiştir. Görselleştirmedeki kelimenin boyutu, kelimenin giriş metnindeki görünme sayısı ile orantılıdır. Başka bir ifade ile frekansı büyük olan metaforun, görseldeki boyutu da büyük olarak belirlenmektedir (Bletzer, 2015). Ayrıca araştırmada konuyla ilişkili olduğundan "kayırmacılık" görseli kullanılmıştır.

\section{Geçerlik ve Güvenirliği Sağlama Aşaması}

Nitel bir araştırmada geçerliğin önemli ölçütleri arasında yer alması nedeniyle toplanan veriler ayrıntılı olarak rapor edilmiş ve sonuçlara nasıl ulaşıldığı açılanmıştır (Yıldırım ve Şimşek, 2016). Hazırlanan bu raporlar yine aynı kapsamda uzman görüşü alabilmek için alanda daha önce metafor çalışması yapan bir uzmana gönderilmiştir. Uzmandan, kategoriler altında toplanan metaforların hiçbiri dışarda kalmayacak biçimde kategorilere yerleştirmeleri istenmiştir. Ayrıca, kategoriler altında toplanan metaforların, kategoriyi temsil edip etmediğini teyit etmek amacıyla dönütler istenmiştir. Araştırmacı, verdiği derslerden birinde katılımcı teyidi alabilmek amacıyla konuyu öğrenciler ile tartışmış ve olumlu dönütler almıştır. Daha sonra uzman tarafından oluşturulan kategoriler ile araştırmacı tarafından yapılıış olan kategorilerin karşılaştırması yapılmıştır. Yapılan bu karşılaştırılma ile görüş birliği ve görüş ayrılığı frekansları belirlenmiş ve araştırmanın güvenirliği sağlanmaya çalışılmıştır. Nitel araştırmalarda, uzman ve araştırmacı değerlendirmeleri arasındaki uyumun \%90 ve üzeri olması arzu edilen düzeyde bir güvenirlik olduğu belirtilmektedir (Saban, 2008). Araştırmanın güvenirliği; Miles ve Huberman'ın (1994) formülü; [Güvenirlik= Görüş Birliği / (Görüş birliği+ Görüş ayrılığı ${ }^{*} 100$ ] kullanılarak hesaplanmıştır. Kayırmacılık araştırması için güvenirlik $\left(146 / 159^{*} 100\right)=\% 93$ oran ile sağlanmıştır. Araştırmanın son aşamasında, elde edilen verilerin frekansları (f) hesaplanmıştır.

\section{Araştırmacının Rolü}

Araştırmacı araştırmada veri toplarken, verileri analiz ederken, yorumlarken ve yazıya geçirirken kendi şahsi görüş ve düşüncelerini araştırma dışında tutmuş, önyargilardan uzak bir şekilde objektif olarak çalışmayı yazıya geçirmeye çalışmıştır. Araştırma içerisinde etik unsurlara dikkat edilmiş, öğrencilerin bölüm bilgileri, isimleri gizli tutulmuş, kişisel bilgilerini içerecek ifadelerden kaçınılmıştır. Araştırma için ilgili komisyondan yazılı izin ve etik kurul izni alındıktan sonra, araştırmacı çalışmasına başlamıştır. 


\section{Bulgular}

Bu başlık altında oluşturulan form aracılı̆̆ıyla elde edilen verilerin analizi sonucu ortaya çıan bulgular sunulmuştur. Elde edilen bulgular, araştırma soruları dikkate alınarak oluşturulan alt başlıklar yardımıyla açıklanmıştır.

\section{Öğrenciler Tarafından Oluşturulan Metaforlar}

Üniversite öğrencilerinin oluşturmuş oldukları metaforlar kelime bulutu aracıllğıyla şekil 1' de sunulmuştur.

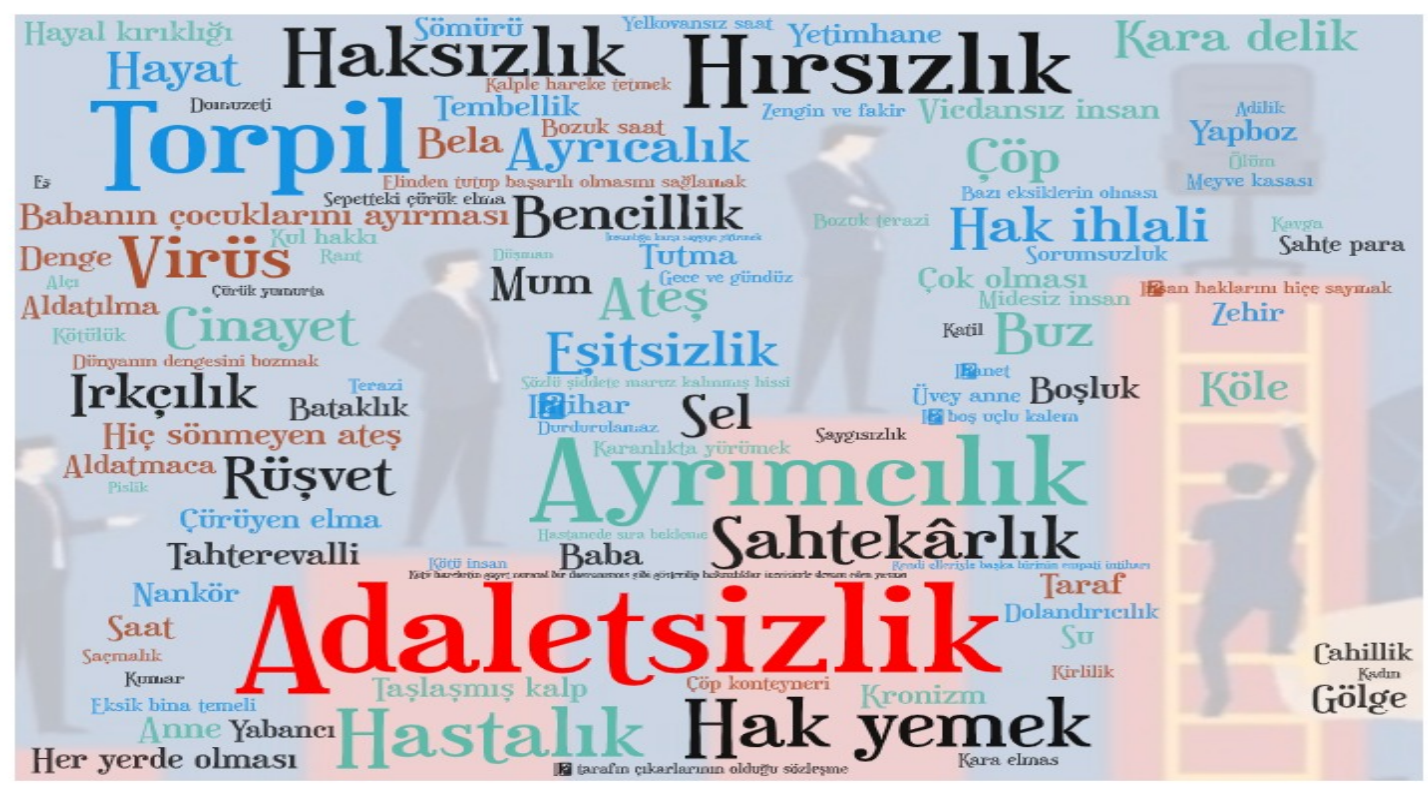

Şekil 1. Üniversite öğrencilerinin kayırmacılık kavramına yönelik ürettikleri metaforlar

Şekil 1'de üniversite öğrencileri tarafından "Kayırmacılık" kavramına ilişkin toplam 110 farklı metafor üretildiği görülmektedir. Kayırmacılık kavramına yönelik en fazla üretilen metaforlar; adaletsizlik ( $f=13)$, torpil $(f=9)$, ayrimcllk $(f=8)$, hirsızlik $(f=6)$, hak yemek $(f=4)$, haksızlik $(f=4)$, hastalik $(f=4)$, sahtekârlik $(f=3)$, virüs $(f=3)$, bencillik $(f=2), \operatorname{rrkçıllk~}(f=2)$, kara delik $(f=2)$, eşitsizlik $(f=2)$, hak ihlali $(f=2)$, ayricalık $(f=2)$, rüşvet $(f=2)$ ve cinayet $(f=2)$ şeklinde olmuştur.

\section{Oluşturulan Kavramsal Kategoriler}

Katılımcıların kayırmacılık kavramına ilişkin oluşturdukları metaforlar analiz edildiğinde, oluşturulan kavramsal kategorilerin frekansları Tablo 2' de sunulmuştur.

Tablo 2. Kayırmacilık Kavraminin Kategorileri

\begin{tabular}{|c|c|c|c|}
\hline Kategori (Alintılar) & Metaforlar & $\mathbf{M}$ & $\mathrm{f}$ \\
\hline $\begin{array}{l}\text { Eşitsizliğin, adaletsizliğin ve ayrımcılığın olması, } \\
\text { "Kayırmacılık torpile benzer, çünkü parası olan diğerlerinden } \\
\text { ayrı tutulur (82K)." "Kayırmacılık ayrtmcıllk gibidir, çünkü } \\
\text { kökünde adaletsizlik vardır (92K)." }\end{array}$ & $\begin{array}{l}\text { (1): Irkçlık, kadın, kalple hareket etmek, tahterevalli, taraf tutma, } \\
\text { elinden tutup başarılı olmasını sağlamak, saçmalık, zengin ve } \\
\text { fakir, adilik, taşlaşmış kalp, alçı, yetimhane, rüşvet, terazi, ihanet, } \\
\text { bozuk terazi, kul hakkı, köle, aldatmaca, kronizm, eş; (2): } \\
\text { Eşitsizlik, ayrıcalık; (3): Sahtekârlık, haksızlık; (8): Torpil, } \\
\text { ayrımclık; (13): Adaletsizlik }\end{array}$ & 28 & 60 \\
\hline
\end{tabular}


Hak edenin emeğinin çalınması ve yaşamdan soğutması, "Kayırmacıllk hırsızlık gibidir, çünkü bir insanın emeklerini, hayallerini ve umutlarmı çalmaktadır (210K)." "Kayırmacılık haksızlık gibidir, çünkü çok çalı̧an emek veren birinin yerine bilgisiz birinin geçmesi (202K)." "Kayırmacılık katile benzer, çünkü birini diğerinden kayırırsan gururunu, kendine olan güvenini de öldürmüş olursun (143K)."

"Kayırmacılık buz gibidir, çünkü insanları hayattan soğutur (149K)."

Büyük zarar vermesi, "Kayırmacılık sepetteki çürük elmaya benzer, çünkü yanındakileri de beraberinde bozar (142K)."

"Kayırmacılık cinayet gibidir, çünkü insan hakkı yemek ve insanın değerlerini öldürmektir (216K)."

Meşru ve sürekli olması, "Kayırmacllk iç sönmeyen ateşe benzer, çünkü her zaman her yerde karşımıza çıkar. Yanında durunca isiniriz iyi oldu zannederiz fakat bir süre sonra o ateş bizi yakıp kül eder (154K)." "Kayırmacılık hayat gibidir, çünki hayatın her alaninda rastliyoruz artık. Insanlar hayat felsefesi yapmışlar (110K)."

Haksız kazanç, "Kayırmacılık sahte para gibidir, çünkü alnının hakkıyla değil kısa yoldan dolandırıcılığa giren bir haksız kazanç gibidir (145K)." "Kayırmacılık hak yemek gibidir, çünkü hakk olmayana hak sağlamaktır (148K)."

Değersiz ve iğrenç olması, "Kayırmacllık kara elmasa benzer, çünkü adında elmas vardır ama gerçekte o kadar değerli ve önemli değildir (67K)." "Kayırmacılık domuz eti gibidir, çünkü teoride de uygulamada da iğrençtir (48K)."

Liyakate bakılmıyor olması, "Kayırmacıllk ırkçılık gibidir, çünkü kişiliğine, becerisine bilgisine, yeteneğine bakılmaksızın kendisinin istediği kişiyi alır (224K)." "Kayırmacılık yapboza benzer, çünkü ait olmayan parçayı zorla olur diye başka yere eklemektir (207K)."

İki taraflı olması, "Kayırmacılık iki tarafın çıkarlarının olduğu bir sözleşme gibidir, çünkü doğal olarak bir çıkar elde edilmektedir (73K)."
(1): Hastanede sıra bekleme, tembellik, dünyanın dengesini bozmak, çürük yumurta, üvey anne, gece ve gündüz, insan haklarını hiçe saymak, torpil, adaletsizlik, kötülük, haksızlık cahillik, aldatılma, hayal kırıklığı, saygısızlık, bazı eksiklerin olması, sözlü şiddete maruz kalınmış hissi, katil, boşluk, kendi elleriyle başka birinin empati intiharı, gölge, yabancı, karanlıkta yürümek, cinayet; (2): Hak yemek, buz, hak ihlali; (6): Hirsızlık

(1): Ölüm, vicdansız insan, çürüyen elma, nankör, intihar, kumar, kirlilik, düşman, kötü insan, pislik, mum, eksik bina temeli, sepetteki çürük elma, zehir, bataklık, meyve kasası, denge, sel, bela, sorumsuzluk, cinayet, kavga, (2): Karadelik, çöp, ateş; (3): Virüs; (4): Hastalık

(1): Babanın çocuklarını ayırması, anne, hiç sönmeyen ateş, baba, her yerde olması, çok olması, saat, kötü bir hareketin gayet normal bir davranışmış gibi gösterilip haksızlıklar içerisinde devam eden bir yaşam, midesiz insan, bozuk saat, durdurulamaz, su; (2): Hayat

(1): Dolandırıcılık, sahte para, sömürü, rant; (2): Hak yemek

(1): Kara elmas, içi boş uçlu kalem, yelkovansız saat, domuz eti, çöp konteyneri

(1): Irkçllık, yapboz

Not: Alıntılar, tabloda kategorilerin altında yer almaktadır. Parantez içindeki her sayı metaforun frekansını belirtir.

Tablo 2' de Kayırmacılık kavramına yönelik metaforların oluşturduğu kategoriler sunulmuştur. Tablo incelendiğinde frekans bakımından; eşitsizliğin, adaletsizliğin ve ayrımcilı̆̆ın olması $(f=60)$, hak edenin emeğinin çalınması ve yaşamdan soğutması ( $f=36)$, büyük zarar vermesi $(f=35)$, meşru ve sürekli olması $(f=14)$, haksız kazanç $(f=6)$, değersiz ve iğrenç olması $(f=5)$, liyakate bakılmıyor olması $(f=2)$ ve iki taraflı olması $(f=1)$ kategorilerinin olduğu görülmektedir.

\section{Sonuç ve Tartışma}

Araştırmada, üniversite öğrencileri tarafından "kayırmacılık" kavramına ilişkin toplam 110 farklı metafor üretildiği görülmektedir. Öğrenciler tarafından en fazla üretilen adaletsizlik metaforu olduğu görülmektedir. Araştırmadaki bulgulardan hareketle öğrenciler genel olarak; kayırmacılığın, eşitsizlik ve ayrımcılıktan dolayı adaletsiz bir davranış olduğunu, hak eden kişinin emeğinin çalındığını ve hayattan soğuduğunu, topluma büyük zararlar verdiğini ve Türk toplumunda meşru ve sürekli olan sosyal bir davranış olduğunu ifade etmişlerdir.

Araştırmada; eşitsizliğin, adaletsizliğin ve ayrımcılı̆̆ın olması, haksız kazanç ve liyakate bakılmıyor olması kategorilerinin altında toplanan metaforlar incelendiğinde, kayırmacılık kavramına ilişkin öğrencilerin, adaletsiz, ayrımcı, haksızlık ve eşitsizliği anımsatan sahtekârca bir davranış olarak algıladıkları tespit edilmiştir. Ayrıca, bahsi geçen kategorilerin tümü birlikte değerlendirildiğinde kayırmacıllı̆ın adaletsizlik algısına sebep olduğu ve adalet algısın doğrudan etkileyen kuvvetli bir değişken olduğu söylenebilir. Nitekim literatürde, kayırmacılık ile adalet arasında ciddi bir ilişkinin varlı̆̆ına vurgu yapıldığı ve bu durumun araştırmanın sonuçları ile örtüştüğü görülmektedir (Asunakutlu ve Avcı, 2010; Polat ve Kazak, 2014). Ayrıca literatürde, 
kayırmacı tutum ve davranışların, adalet eksikliğine yol açttğ 1 ve çalışanların eşitlik algısını olumsuz yönde etkilediği belirtilmektedir (Araslı ve Tümer, 2008; Asunakutlu, 2010; Aydoğan, 2009; Büte ve Tekarslan, 2010; Çelik ve Erdem, 2012; Ekmekçi, 2014; Karataş, 2013; Keleş, Özkan ve Bezirci, 2011; Küçükkaraduman, 2006; Özler ve Büyükarslan, 2011; Polat, 2013; Polat ve Kazak, 2014). Yapılan araştırmalar incelendiğinde, kayırmacılığın, bireylerin özellikle adalete olan inancının azalmasına sebep olduğu ve bu sebeplerin de verimsizlik sonucunu doğurduğu söylenebilir.

Araştırmada, adaletsizlik, torpil, hırsızlık, hak yeme, haksızlık, sahtekârlık, bencillik, ırkçıllk, kara delik, eşitsizlik, hak ihlali, ayrıcalık, rüşvet ve cinayet gibi metaforların sıklıkla kullanıldığı görülmektedir. Yönetsel yolsuzluğun bir türü olan kayırmacılık, günümüz Türkiye'sinde araştırmadakine benzer şekilde toplum içinde daha çok "torpil" olarak adlandırılmaktadır (Aktan, 2001; Aytaç, 2010a; Çoban, 1999; İlhan ve Aytaç, 2010; Özsemerci, 2002). Kayırmacılık, bir kişi veya grubun çıkar sağlamasına yönelik olarak yapılan hak ve adaletten sapma eğilimidir (Aytaç, 2010a). Menfaat sağlama üzerine birilerine öncelik tanımak ve ayrıalık sağlamaktır. Ayrıcalıklı ve öncelikli davranıştan fayda gören örgüt veya birey arasındaki yakın ilişki ağları etrafında oluşturulan çarpık bir ilişki şeklidir ve kronizm, nepotizm gibi dayanakları ile çeşitli şekillerde vuku bulabilmektedir. Bu bağlamda kayırmacılık kavramının tanımları ile araştırmada üretilen metaforlar karşılaştırıldığında örtüştüğü, fakat oluşturulan ayrımcılık gibi bazı metaforların ise kısmen örtüşmediği görülmektedir. Kayırmacılık kavramı çok fazla olmasa da ayrımcılık ile birlikte kullanılır. "Fark gözetme, eşit muamele etmeme" (TDK, 2021; Zeytinoğlu, 2010) olarak da ifade edilen ayrımcllık, kayırmacılık ile benzer anlamda kullanıldığı gözlenmektedir. Bu kavramlar bireye vermiş olduğu fayda ve zarar bakımından birbirinden farklılaşmaktadır. Ayrımcılık daha çok aşağılama kötü düşünme gibi olumsuz durumlar ya da olaylar için kullanılırken; kayırmacılık, iltimas geçme ya da hiç hak etmediği şekilde üstün tutma gibi olumlu denilebilecek durumlar veya olaylar için kullanılmaktadır. Bu bağlamda, ayrımcılık gören kişi zarar görür iken, kayırmacılık yapılan kişi ise fayda sağlamaktadır. En basit ifade ile ayrımcllık hak edilmeyen bir cezalandırma iken kayırmacılığın hak edilmeyen bir ödül olduğunu söylemek mümkündür.

Hak edenin emeğinin çalınması ve yaşamdan soğutması kategorisinin metaforları, hak eden-kayıran-kayırılan üçlü ilişkisi bağlamında incelendiğinde; kayırmacıllğın, hak eden kişinin hakkının çalınması ve hayattan soğutması, kayıran kişinin haksızlık yapması ve hak etmeyen kişiye ayrıcalık tanınması gibi durumların hem konu bakımından hem de etkileme bakımından ne kadar kapsamlı ve sosyal bir kavram olduğunu göstermektedir (İlhan ve Aytaç, 2010). Kayırmacilığın ortaya çıkmasında en önemli tarafın kayırmacılığı yapan taraf, en kazançlı tarafın kayırılan taraf ve en zararlı tarafın ise unutulan, kayırmacılığın mağduru olan ve hakkı çalınan taraf olduğu söylenebilir. Demokratik bir toplumda hakkı elinden alınan kişinin, hakkını savunmak ve iade etmek dördüncü taraf olarak isimlendirilen diğer vatandaşların görev ve sorumluluğunda olduğu düşünülmektedir. Ayrıca, hakkı elinden alınan kişinin durumu adaletsizlik olarak nitelendirileceğinden bu konudaki yetkililerinin de adaletin gereği olarak hakkın teslim edilmesi noktasında duruma müdahil olmaları ve hakkını teslime etmeleri gerekmektedir (Demirbilek, 2021b). Aksi halde araştırmanın verileri doğrultusunda, kayırılan tarafın, hak etmediği bir şekilde ayrıcalık, öncelik, imtiyaz gibi davranış ve eylemlerden fayda sağladığı ve mutlu olduğu, hakkı elinden alınan taraf açısından ise emeğinin çalındığı, yaşamdan soğuduğu ve çok üzüldüğü söylenebilir.

Öğrenciler, kayırmacılığın ölüm, cinayet, intihar, zehir, kavga, kirlilik, düşman, kötü insan, pislik, mum gibi metaforlar ile çok kötü sonuçlarının olduğunu; çürüyen elma, pislik, sepetteki çürük elma, meyve kasası, denge, sel, bela, sorumsuzluk, çöp, ateş, virüs, hastalı gibi metaforlar ile bireysel bir davranış olmadığını, sosyal bir davranış olduğunu ve tüm toplumu olumsuz etkilediğini; vicdansız insan, nankör, kumar, düşman, kötü insan, eksik bina temeli, bataklık, gibi metaforlar ile de toplumların gelişmiş̧liğini ve güvenliğini tehdit ettiğini ifade etmişlerdir. Nitekim kayırmacılık literatürde; toplumların gelişmişliğini ve güvenliğini tehlikeye sokması, toplumsal ve ekonomik büyümeyi tehdit etmesi, demokrasiyi zayıflatması, etik ve ahlaki değerlerin yozlaştırması ve sosyal adalete büyük zararlar vermesi nedeniyle en büyük problemlerden biri olarak gösterilmektedir (Karakaş ve Çak, 2007).

Araştırmanın metaforları genel olarak incelendiğinde; Sahtekârlık, adilik, kötülük, hırsızlık, vicdansız, nankör, kötü insan, pislik, dolandırıcı, sahte, ırkçıllk, gibi metaforlar kullanıldığ görülmektedir. Bu metaforlardan hareketle kayırmacılık, etik ve ahlaki olmayan sahtekarca bir davranış olarak nitelendirilebilir. En temelde 
adalet algısını izale (Yok etme) eden bu sosyal davranış bozukluğu hem bireysel ve hem de toplumsal ahlakı, erozyona uğratmaktadır. Literatürde, adalet ile ahlak arasında güçlü, pozitif ve anlamlı bir ilişkinin varlığına vurgu yapıldığı ve bu durumun araştırmanın sonuçları ile örtüştüğü görülmektedir (Akbaşlı, Erçetin ve Kubilay, 2019). Bu türdeki sosyal davranış bozukluklarının toplumda maddi ve manevi zararlara neden olduğu ve bunun bütün ülkeyi etkilediğine dikkat çekmek gerekir. Nitekim mikro (bireysel) düzeyde başlayan bir uygulama olan kayırmacılığın, makro (toplumsal, ülkesel) düzeyde etkiler yaratabilecek bir niteliğe sahip olduğu söylenmektedir (Demirbilek, 2021b). Birçok ülkede, özellikle gelişmemiş ülkelerde, verimlilik kaybının önemli sebebi (Kim, 2007) olarak kayırmacılık gösterilmekte, ayrıca kişilerin adalet duygusuna ve yönetime duyulan güvene zararlar vermektedir. Sonuç olarak Muş Alparslan Üniversitesi öğrencilerinin ifadelerinden hareketle kayırmacılığın, çok kötü sonuçları olan sosyal bir davranış bozukluğu olduğu, toplumların gelişmişliğini ve güvenliğini tehdit ettiğinden dolayı tüm toplumu olumsuz etkilediği sonucuna varılmıştır.

Araştırmada meşru ve sürekli olması kategorisinin altında toplanan metaforlar incelendiğinde öğrencilerin, kayırmacıllğı meşru ve sürekli bir şekilde uygulanan bir davranış olarak algıladıkları tespit edilmiştir. Bu şekilde inanıyor ve algılıyor olmalarının; Türk toplumunun sahip olduğu yüksek güç mesafesi ve paternalist eğilimlerin, üniversite örgütlerindeki izdüşümünden kaynaklandığı düşünülmektedir. Zira literatürde, Türk toplumunun sosyal ve kültürel dokusunda, güç mesafesinin, paternalist eğilimlerin ve toplulukçu boyutun yüksek düzeyde olduğu ifade edilmektedir (Aycan ve Kanungo, 2000; Erben, 2004; Hofstede ve Hofstede, 2005; Paşa, 2000; Sargut, 2010).

Kayırmacılığın, Türk toplumunda baba, anne şeklinde yakıştırmalarda bulunulan güçlü kişilerin meşru hakkı olarak görüldüğü söylenmektedir. "Güçlü olanların ayrıcalıkları vardır." ve "Hakkıdır, yapar." gibi söylemlerin kabul edildiği Türk toplumunda, kayırmacı davranış sergileyenlerin ne kadar güçlü oldukları meşruluğu belirleyen en önemli faktörler arasında gösterilmektedir. Kayıran/kayırılan kişi kendisinden çok güçlü ve kendisine yakın ise meşru olarak görülmekte, çok güçlü ve kendisine yakın olmayanlar ise gayrı meşru olarak görülmektedir (Demirbilek, 2021b). Araştırmada, Muş Alparslan Üniversitesi öğrencilerinin Türk toplumunun benimsemiş olduğu yüksek güç mesafesini kendi üniversite örgütlerine yansıttığı saptanmıştır. Araştırmaya katılan öğrencilerin, güçlü olan kişilerin sergilemiş olduğu kayırmacı davranış ve tutumlarını meşru olarak gördükleri tespit edilmiştir.

Ayrıca öğrenciler tarafından üretilen, hiç sönmeyen ateş, baba, her yerde olması, çok olması, saat, su ve hayat gibi metaforlar değerlendirildiğinde, toplum içinde sürekli olarak kullanılan bir davranış olduğu ifade edilebilir. Türk toplumunun "İlişkiler, başarı ve liyakatten ya da işin kendisinden çok daha önemlidir" ya da "Başarı çok çalışmaktan ziyade ilişkiler ve şansa bağlıdır" (WVSD) şeklinde düşünen toplumsal bir yapıya sahip olduğu aktarılmaktadır (Demirbilek, 2021b). Bu deyimler ve özdeyişler son derece kabul görmekte ve herkes aynı anlamı yükleyebilmektedir. Burada Türk toplumunu kültürel anlamdaki kodlarının neye veya nelere tekabül edebileceğini tekrar düşünüp kayırmacılık fiiline meşruiyet kazandıran hususlar ele alınarak toplumsal kalkınmaya zarar verecek durumların önüne geçilmelidir. Ayrıca kayırmacılı̆̆ın deyimlere ve özdeyişlere dönüşmüş olması araştırmacıları, konunun tarihçesi ve kronik bir sorun olduğu noktasında da aydınlatmaktadır. Sonuç olarak öğrencilerin, sosyal gerçekliğimiz olan kayırmacılığın Türk toplumunda meşru ve sürekli bir biçimde uygulanan bir davranış olduğu algısına sahip oldukları tespit edilmiştir.

Kayırmacılığın bu denli olumsuz etkisinin olmasından dolayı kavram ile ilgili yapılan her araştırma önem arz etmektedir. Bu sebeple uygulayıcılara ve araştırmacılara şu önerilerde bulunulabilir; Öğrencilerin "kayırmacılık" kavramına yönelik algıları ortaya çıkarmak için nicel ve karma yöntemler ile araştırmalar yapılabilir. Akademisyenlerin "kayırmacılık" kavramına yönelik algıları ortaya çıkarılabilir. Kayırmacılık kavramı, sosyal adalet, güven, ahlak, ayrımcıllk ve eşitlik algısı gibi kavramlar ile aralarındaki ilişkiler incelenebilir. Ayrıca öğrencilerin; liyakat, sosyal adalet ve eşitlik gibi kavramlara yönelik algılarını ortaya çıkarabilmek için metafor araştırmaları yapılabilir. Aynı araştırma, farklı kişilerle farklı üniversitelerde ve farklı yönetici konumları ile tekrarlanabilir. Araştırmada ön plana çıkan adalet ve liyakat ile ilgili araştırmalara ağırlık verilebilir. 


\section{Nesip DEMIRBILEEK}

\section{Yazarın Beyanı}

Araştırmacıların katkı oranı beyanı: Araştırmanın tüm aşamaları yazar tarafından yapılmıştır.

Etik Kurul Kararı: Araştırma verilerinin toplanması için Bingöl Üniversitesi Etik Onay Kurulu'ndan (Sayı:92342550/108.01/) izin alınmıştır.

Çatışma beyanı: Herhangi bir kişi, kurum ya da kuruluşla çıkar çatışması bulunmamaktadır.

Destek ve teşekkür: Araştırma için herhangi bir kurum ya da kuruluştan destek alınmamıştır.

\section{Kaynaklar}

Abdalla, F. H., Maghrabi, S. \& Raggad, G. B. (1998). Assessing the perceptions of human resource managers toward nepotism: A cross-cultural study. International Journal of Manpower, 19(8), 554- 570.

Akalan, A. (2006). Türk kamu hizmetinde iyi yönetim ve yolsuzlukla mücadele. (Yayımlanmamış doktora tezi). Selçuk Üniversitesi Sosyal Bilimler Enstitüsü, Konya.

Akbaşl1, S., Erçetin, Ş. Ş. \& Kubilay, S. (2019). Relationship between prospective teachers' deontic justice attitudes and academic dishonesty tendencies. South African Journal of Education, 39(3), 1622.

Aktan, C. C. (2001). Siyasal ahlak ve siyasal yozlaşma. C. C. Aktan (Ed.), Yolsuzlukla mücadele stratejileri (s. 51 - 69) içinde. Ankara: Hak - İş Yayınları.

Arasl1, H., \& Tümer, M. (2008). Nepotism, favoritism, and cronyism: A study of their effects on job stress and job satisfaction in the banking industry of North Cyprus. Social Behavior and Personality, 36(9), 1237 - 1250.

Argon, T. (2016). Öğretmen görüşlerine göre ilkokullarda yöneticilerin kayırmacılık davranışları. Kastamonu Ĕ̆itim Dergisi, 24(1), 233-250.

Arslan, M. M., \& Bayrakçı, M. (2006). Metaforik düşünme ve öğrenme yaklaşımının eğitim-öğretim açısından incelenmesi. Milli Ĕ̆gitim, 35(171), 100-108.

Asunakutlu, T. (2010). Kayırmacilı̆̆ın temelleri: Benzerlik ve benzemezlik. R. Erdem (Ed.), Yönetim ve örgüt açısından kayırmacılık içinde. (s. 41 - 60). İstanbul: Beta Yayıncılık.

Asunakutlu, T., \& Avc1, U. (2010). Aile işletmelerinde nepotizm algısı ve iş tatmini ilişkisi üzerine bir araştırma. Süleyman Demirel Üniversitesi İktisadi ve İdari Bilimler Fakültesi Dergisi, 15(2), 93-109.

Aycan, Z., \& Kanungo, R., N. (2000). Toplumsal kültürün kurumsal kültür ve insan kaynakları uygulamaları üzerine etkileri. Zeynep Aycan, (Ed.), Akademisyenler ve profesyoneller bakış açısıyla Türkiye'de yönetim, liderlik ve insan kaynakları uygulamaları, (s. 25 - 53) içinde. Ankara: Türk Psikologlar Derneği Yayınları.

Aydoğan, İ. (2009). Favoritism in the Turkish Educational System: Nepotism, cronyism, and patronage. Educational Policy Analysis and Strategic Research, 4(1), 19-35.

Aytaç, Ö. (2010a). Kayırmacı ilişkilerin sosyolojik temeli. R. Erdem (Ed.), Yönetim ve örgüt açısından kayırmacılık (s. 3 - 26) içinde. İstanbul: Beta Yayıncılık.

Aytaç, Ö. (2010b). Bürokratik kayırmacılık: Enformel bağlayıcılıkların yönetim ilişkilerine etkisi. R. Erdem (Ed.), Yönetim ve örgüt açısından kayırmacılık (s. 86-109) içinde. İstanbul: Beta Yayıncılık.

Balcı, A. (2016). Sosyal bilimlerde araştırma yöntem teknik ve ilkeler. Ankara: Pegem Akademi Yayıncılık.

Bayhan, V. (2002). Demokrasi ve sivil toplum örgütlerinin engelleri: Patronaj ve nepotizm. Cumhuriyet Üniversitesi Sosyal Bilimler Dergisi. 26(1), 1-13.

Berkman, Ü. (1983). Azgelişmiş ülkelerde kamu yönetiminde yolsuzluk ve rüşvet. Ankara: Türkiye ve Orta Doğu Amme İdaresi Enstitüsü Yayınları.

Bletzer, K. V. (2015). Visualizing the qualitative: Making sense of written comments from an evaluative satisfaction survey. Journal of Educational Evaluation for Health Professions, 12(12), 1-8. 
Büte, M. (2011). Kayırmacılığın çalışanlar üzerine etkileri ile insan kaynakları uygulamaları ilişkisi: Türk kamu bankalarına yönelik bir araştırma. Atatürk Üniversitesi Sosyal Bilimler Enstitüsü Dergisi, 15(1), 383 - 404.

Büte, M., \& Tekarslan, E. (2010). Nepotizmin çalışanlar üzerine etkileri: Aile işletmelerine yönelik bir saha araştırması, Ekonomik ve Sosyal Araştırmalar Dergisi, 6(1), 1-21.

Büyüköztürk, Ş., Kılıç-Çakmak, E., Akgün, Ö., Karadeniz, Ş. \& Demirel, F. (2008). Bilimsel araştırma yöntemleri. Ankara: Pegem Akademi Yayıncilı.

Creswell, J. W. (2017). Araştırma deseni nitel nicel ve karma yöntem yaklaşımları. S. B. Demir, (Çev. Ed.), 3. Baskı, Ankara: Eğiten Kitap.

Çarıkçı, İ. H. \& Arslan, E. T. (2010). Türk yönetim geleneğinde kayırmacıllğın tarihi seyri. R. Erdem (Ed.), Yönetim ve örgüt açısından kayırmacılık (s. 27 - 39) içinde. İstanbul: Beta Yayıncllık.

Çelik, K.\& Erdem, A. R. (2012). Üniversitede çalışan idari personele göre "Kayırmacılık". Akdeniz Ĕ̆itim Araştırmaları Dergisi, 11, 23-30.

Çoban, O. (1999). Bir siyasal yozlaşma türü olarak rüşvet ve ekonomik etkileri. Cumhuriyet Üniversitesi, iktisadi ve İdari Bilimler Dergisi, 13(1), 173-193.

Demirbilek, N. (2020). Üniversite öğrencilerinin gözüyle üniversite kavramı. OPUS Uluslararası Toplum Araştırmaları Dergisi, 16(Eğitim Bilimleri Özel sayısı), 5585 - 5607.

Demirbilek, N. (2021a). Üniversite öğrencilerinin uzaktan öğretime ilişkin metaforik algıları/Metaphoric perceptions of university students on distance education. $e$-Uluslararası Ĕ̆itim Araştırmaları Dergisi, 12(1), $1-15$.

Demirbilek, N. (2021b). Türk kültüründe kayırmacılık: Teori araştırma ve uygulama. Ankara: Pegem Akademi Yayıncilik.

Demirbilek, N., \& Korkmaz, C. (2021), C. Study concept as a metaphor from the lenses of university students. African Educational Research Journal, 9(1), 227-236.

Demirtaş, H., \& Demirbilek, N. (2019). Okul müdürlerinin kayırmacı davranışlarının öğretmenlerin örgütsel adalet algıları ile müdüre güvene etkisi. B.U. Journal of Social Sciences Institute/B.Ü. Sosyal Bilimler Enstitüsü Dergisi, 9(17), 111-142.

Demirtaş, H., \& Çoban, D. (2014). Üniversite öğrencilerinin, üniversite ve fakülte kavramlarına ilişkin metaforları (İnönü Üniversitesi örneği). Ondokuz Mayıs Üniversitesi Ĕ̆itim Fakültesi Dergisi, 33(1), 113-144.

Ekmekçi, M. (2014). Değişim mühendisliği, nepotizm ve mobbingin çalşan performansı üzerindeki etkisi. (Yayımlanmamış yüksek lisans tezi). Beykent Üniversitesi, İstanbul.

Erben, G., S. (2004). Toplumsal kültür aile kültürü etkileşimi bağlamında paternalizm boyutuyla işletme kültürü: Türkiye örneği, 1. Aile İşletmeleri Kongresi Bildirileri, 17-18 Nisan 2004, T. Koçel, (Ed.), İstanbul: İstanbul Kültür Üniversitesi Yayınları: 345-356.

Erdem, R. (2010). Kayırmacılık/ayrımcılık. R. Erdem (Ed.), Yönetim ve örgüt açısından kayırmacılık (s. 1 - 2.) içinde. İstanbul: Beta Yayıncıllk.

Erden, P. S. (2014). Paternalistik liderlik ile iş ayrımcılığı algısı ve kayırmacılık (nepotizm) arasındaki ilişki. (Yayımlanmamış yüksek lisans tezi). Yeditepe Üniversitesi, İstanbul.

Fraenkel, J. R., Wallen, N. E. \& Hyun, H. H. (1993). How to design and evaluate research in education (Vol. 7). New York: McGraw-Hill.

Geçer, A. (2015). Liselerde çalışan öğretmenlerin kayırmacllk ve örgütsel destek alğ düzeyleri (Muğla ili örneği). (Yayımlanmamış yüksek lisans tezi). Muğla Sıtkı Koçman Üniversitesi. Muğla

Güveli, E., İpek, A. S., Atasoy, E. \& Güveli, H. (2011). Sınıf öğretmeni adaylarının matematik kavramına 
yönelik metafor algiları. Turkish Journal of Computer and Mathematics Education, 2(2), 140-159.

Hofstede, G. \& Hofstede, G. (2005). Cultures and organizations: Software of the mind, revised and expanded (2nd Ed.). New York: McGraw-Hill.

İlhan, S. \&Aytaç, Ö. (2010). Türkiye'de kayırmacı eğilimlerin oluşmasında toplumsal ve kültürel yapının rolü. R. Erdem (Ed.), Yönetim ve örgüt açısından kayırmacılık (s. 61 - 83.) içinde. İstanbul: Beta Yayıncılık.

Kalyoncu, R. (2012). Görsel sanatlar öğretmeni adaylarının öğretmenlik kavramına ilişkin metaforları. Mustafa Kemal Üniversitesi Sosyal Bilimler Enstitüsü Dergisi, 9(20), 471-484.

Karakaş, M. \& Çak, M. (2007). Yolsuzlukla mücadelede uluslararası kuruluşların rolü. Maliye Dergisi, 153, 74101.

Karaköse, T. (2014). The effects of nepotism, cronyism and political favoritism on the doctors working in public hospitals. Ethno Med, 8(3), 245-250.

Karataş, A. (2013). Otel işletmelerinde kronizmin iş tatmini ve işten ayrılma niyeti üzerine etkisi. (Yayımlanmamış yüksek lisans tezi). Balıkesir Üniversitesi, Balıkesir.

Kayabaşı, Y. (2005). Politik yozlaşmaya çözüm olarak anayasal iktisat. (Yayımlanmamış yüksek lisans tezi). Çukurova Üniversitesi, Adana.

Keleş, H. N., Özkan, T. K. \& Bezirci, M. (2011). A study on the effects of nepotism, favoritism, and cronyism on organizational trust in the auditing process in family businesses in Turkey. International Business $\mathcal{E}$ Economics Research Journal, 10(9), 9-16.

Kılcan, B. (2017). Metafor ve eğitimde metaforik çalışmalar için bir uygulama rehberi. Ankara: Pegem Akademi Yayincilik.

Kim, K. (2007). Favoritism and reverse discrimination. European Economic Review, 51(1), 101-123.

Kurtoğlu, A. (2012). Siyasal örgütler ve sivil toplum örgütleri bağlamında hemşehrilik ve kollamacılık. Ankara Üniversitesi SBF Dergisi, 67(1), 141 - 169.

Küçükkaraduman, E. (2006). İlköğretim okul müdürlerinin etik davranışlarının incelenmesi. (Yayımlanmamış yüksek lisans tezi). Gazi Üniversitesi, Ankara.

Kwon, I. (2006). Endogenous favoritism in organizations. University of Michigan Topics in Theoretical Economics, $6(1), 1-24$.

Lakoff, G. \&Johnson, M. (2015). Metaforlar: Hayat, anlam ve dil. (G. H. Demir, Çev.). İstanbul: İthaki.

Loewe, M., Blume, J. \& Speer, J. (2008). How favoritism affects the business climate: Empirical evidence from Jordan. Middle East Journal, 6(2), 259-276.

Miles, M. \& Huberman, A. M. (1994). Qualitative data analysis: An expanded sourcebook. Sage Publications.

Nalçacı, A. \& Bektaş, F. (2012). Öğretmen adaylarının okul kavramına ilişkin algıları. Ahi Evran Üniversitesi Kırşehir Eğitim Fakültesi Dergisi, 13(1), 239-258.

Özdemir, M. (2012). Lise öğrencilerinin metaforik okul algılarının çeşitli değişkenler bakımından incelenmesi. Eğitim ve Bilim, 37(163), 96-109.

Özkanan, A. \& Erdem, R. (2014). Yönetimde kayırmacı uygulamalar: Kavramsal bir çerçeve. Süleyman Demirel Üniversitesi Sosyal Bilimler Enstitüsü Dergisi, 2(20), 179-206.

Özler, D. E. \& Büyükarslan, A. B. (2011). The overall outlook of favoritism in organizations: A literature review. International Journal of Business and Management Studies, 3(1), 275-285.

Özler, H., Özler, E. D. \& Gümüştekin, G. E. (2007). Aile işletmelerinde nepotizmin gelişim evreleri ve kurumsallaşma. Selçuk Üniversitesi Sosyal Bilimler Enstitüsü Dergisi, 17, 437-450. 
Özsemerci, K. (2002). Türk kamu yönetiminde yolsuzluklar nedenleri zararlar ve çözüm önerileri. Ankara: TC. Sayıştay Başkanlığı Yayını.

Paşa, S., F. (2000). Türkiye ortamında liderlik özellikleri. Zeynep Aycan, (Ed.), Akademisyenler ve profesyoneller bakış açısıyla Türkiye'de yönetim, liderlik ve insan kaynakları uygulamaları (s. 225 - 241.) içinde. Ankara: Türk Psikologlar Derneği Yayınları.

Patton, M. Q. (2014). Qualitative research and evaluation methods: Integrating theory and practice. Sage Publications.

Polat, R. (2013). Ortaöğretim kurumlarında kronizm algısının örgütsel güven üzerindeki etkisi. (Yayımlanmamış yüksek lisans tezi). Fırat Üniversitesi Eğitim Bilimleri Enstitüsü, Elazığ.

Polat, S. \& Kazak, E. (2014). Okul yöneticilerinin kayırmacı tutum ve davranışları ile öğretmenlerin örgütsel adalet algıları arasındaki ilişki. Kuram ve Uygulamada Eğitim Yönetimi Dergisi, 20(1), 71-92.

Saban, A. (2008). Okula ilişkin metaforlar. Kuram ve Uygulamada Ĕ̆itim Yönetimi Dergisi, 14(3), 459-496.

Sargut, A. S. (2010). Kültürler arası farklılaşma ve yönetim. İstanbul: İmge Kitabevi.

Schram, T. H. (2003). Conceptualizing qualitative inquiry. Upper Saddle River, NJ: Merrill Prentice Hall.

Sakçak, A., Arslan, Y., ve Polat, S. (2021). Favoritism behaviors of school principals: teachers' perceptions on the causes and consequences of favoritism in Turkey. Educational Studies, 1-19.

TDK. (2021). Türk Dil Kurumu. Mart 3, 2021 tarihinde http://www.tdk.gov.t. adresinden erişildi.

Tepebaşılı, F. (2013). Metafor yazıları. Konya: Çizgi Kitabevi.

Uçar, A. (2016). Yöneticilerin kayırmacı davranışlarının, örgütsel muhalefet üzerindeki etkisi. (Yayımlanmamış yüksek lisans tezi). Siirt Üniversitesi, Siirt.

Yalçın, M. \& Erginer, A. (2012). Metaphoric perception of principals in primary schools. Journal of Teacher Education and Educators, 1(2), 229-256.

Yıldırım, A. \& Şimşek H. (2016). Sosyal bilimlerde nitel araştırma yöntemleri. (10. bs), Ankara: Seçkin Yayınevi.

Zeytinoğlu, E. (2010). Ayrımcılık yasağına genel bir bakış. İstanbul Ticaret Üniversitesi Sosyal Bilimler Dergisi, 9(18), 115-134. 


\section{EXTENDED ABSTRACT}

\section{Introduction}

It is accepted that the perception that "if you find your fellow, every job can be done" is at a very high level in Turkish society. According to this perception, it is stated that if there is something to be done in public institutions and organizations, a familiar man must be found (Kurtoğlu, 2012). This phenomenon, defined as favoritism, is conveyed as a social reality of Turkish society (Akalan, 2006). As a matter of fact, many researchers draw attention to the prevalence of favoritism because of their studies in public institutions. Comerford (2002), in a study he conducted on Canadian government employees, stated that the second most important source of workplace conflict after workload is favoritism (Kwon 2006). Favoritism, which is accepted as unethical behavior (Polat and Kazak, 2014), is a phenomenon that can be encountered in both organizational and daily life and can occur in almost every area where social systems exist (Özkanan and Erdem 2014). For example, "University Sociological Profile of Youth - 2001", says the study, a questionnaire applied to the students, "Turkey is not hard-working, gaining the uncle" proposition; $90 \%$ of the sample answered "yes". In the study, "What is the real purpose of politicians?" 75\% of the sample to their relatives, supporters, comrades, etc. He replied as gaining an unfair advantage and getting rich. When evaluated statistically, such nepotistic attitudes and behaviors are the sources of very serious problems, and when evaluated in terms of meaning, it is said that they divert society from the goal of progress and disrupt individuals' perception of justice (Polat and Kazak, 2014). Favoritism is seen as one of the forerunners of negative social consequences within organizations (Sakçak, Arslan, and Polat, 2021).

\section{Method}

Phenomenological design, one of the qualitative research methods, was used in the study. Phenomenology is a deliberate experience and social action of individuals' own life worlds (Schram, 2003). This pattern: It is to reveal cognitive structures such as perception and expectation in their minds by examining the explanations of the participants included in the study regarding the facts they have experienced (Creswell, 2017; Patton, 2014).

Easily accessible sampling technique, one of the sampling methods with unknown probability, was used in selecting the participants. With this technique, in determining the participants, a random sample large enough to represent the universe is selected from a universe (Fraenkel, Wallen, and Hyun, 1993). In addition, people who are related to the research subject and whom the researcher can easily reach are used (Yıldırım and Şimşek, 2016). In line with the purpose of the study, 224 students studying at Muş Alparslan University were reached in the 2020-2021 academic year. The students were attained through familiar lecturers working as academicians at Muş Alparslan University. However, the forms of 65 participants who created or did not want to create an erroneous metaphor for the concept of favoritism were eliminated. As a result, the study was conducted with 159 forms.

The content analysis method was used in the analysis of the study. Content analysis is described as a systematic, renewable technique in which codings are made by adhering to certain rules and explains some words of a text with smaller content categories (Büyüköztürk et al. 2008). Balcı (2016) content analysis; defines what people speak and write as a digitization process by encoding them according to explicit statements. The following five-stage evaluation process was used in the content analysis of the research (Creswell, 2017; Demirbilek, 2021a; Saban, 2008): 1. Naming and Screening Stage, 2. Classification Stage, 3. Category Development Phase is the 4th Validity and Reliability Phase, and the 5th Organizing the Data for Quantitative Data Analysis Phase.

\section{Results}

In Figure 1, it is seen that a total of 110 different metaphors related to the concept of "favoritism" are produced by university students. The most frequently produced metaphors for the concept of favoritism; injustice $(f=13)$, favoritism $(f=9)$, discrimination $(f=8)$, injustice $(f=8)$, theft $(f=6)$, disease $(f=4)$, fraud $(f=$ $3)$, virus $(f=3)$, selfishness $(f=2)$, racism $(f=2)$, black hole $(f=2)$, inequality $(f=2)$, violation of rights $(f=2)$ 
privilege $(\mathrm{f}=2)$, bribery $(\mathrm{f}=2)$ and murder $(\mathrm{f}=2)$.

The categories formed by the metaphors for the concept of favoritism are presented in Table 2. When the table is examined in terms of frequency; The existence of inequality, injustice, and discrimination $(f=60)$, the stealing of the labor of the deserving person, and alienation from life $(f=36)$, great harm $(f=35)$, being legitimate and continuous $(f=13)$, unfair gain $(f=6)$, being worthless and disgusting $(f=5)$, not looking at merit $(f=2)$, and having two sides $(f=1)$.

\section{Conclusion}

When the categories are examined, it has been determined that students perceive the concept of favoritism as an unfair, discriminatory, dishonest behavior reminiscent of injustice and inequality. Besides, when all the aforementioned categories are evaluated together, it can be said that favoritism causes the perception of injustice and is a strong variable that directly affects the perception of justice. As a matter of fact, it is seen that there is a serious relationship between favoritism and justice in the literature, and this situation coincides with the results of the study (Asunakutlu and Avc1, 2010; Polat and Kazak, 2014). In addition, it is stated in the literature that clientelistic attitudes and behaviors lead to lack of justice and negatively affect employees' perception of equality (Araslı and Tümer, 2008; Asunakutlu, 2010; Aydoğan, 2009; Büte and Tekarslan, 2010; Çelik and Erdem, 2012; Ekmekçi, 2014; Karataş, 2013; Keleş, Özkan, and Bezirci, 2011; Küçükkaraduman, 2006; Özler and Büyükarslan, 2011; Polat, 2013; Polat and Kazak, 2014;). When we examine the research, it can be said that favoritism causes a decrease in the belief of individuals especially injustice, and these reasons lead to inefficiency. 